\title{
Г.Г.СЕМКИНА
}

Омский государственный университет им. Ф.М.Достоевского

\section{О НЕКОТОРЫХ УСЛОВИЯХ ОБОСОБЛЕНИЯ}

В теории членов предложения обычно обсуждаются две проблемы, связанные с определением: проблема его статуса и проблема его разновидностей. Среди последних, как правило, вскользь упоминается обособленное определение. Между тем, обособленное определение существенно отличается от необособленного по своим характеристикам и функциям. Это связано с трансформированием синтаксических связей при обособлении. Если обычное определение связано с определяемым словом атрибутивной связью подчинительного характера, то в обособленном определении происходит ее преобразование в полупредикативную связь. Об этом явлении писали многие лингвисты (О.С.Ахманова и Г.Б.Микаэлян, В.В.Бабайцева, Н.С.Валгина, Г.А.Вейхман, В.Г.Гак, П.А.Лекант и др.). В частности, отмечается, что атрибутивная связь представлена как данная, она констатирует отнесенность признака предмету вне связи с моментом речи, «ее характерная черта - способность образовывать такие сочетания, которые в предложении выступают как цельные единицы» [Смирницкий 1957: 174]; предикативный же признак не присущ предмету, он приписывается предмету говорящим, причем отнесенность признака к предмету сопоставляется по времени с моментом речи и оценивается говорящим в модальном плане. Важно, что при обособлении определений происходит именно установление, приписывание признака, «...обособление характеризуется нарушением «связного синтаксиса» [Гак 2004:728], что свидетельствует о предикативном характере связи, однако модально-временная оценка при этом зависима от главной предикации, выраженной личной формой глагола. Зависимую форму выражения предикации называют полупредикативной.

В отношении функций обособления обычно высказывается мысль о необходимости в этом случае смыслового выделения данного члена предложения. «Обособление или необособление предопределяется задачами высказывания. Обособление ... всегда связано с тем, что обособленный отрезок внутри предложения актуализируется, приобретает относительную смысловую самостоятельность или несет в себе оттенок дополнительного сообщения» [Грамматика 1970: 643]. «Обособление имеет целью выделить обособляемый элемент и придать ему больший удельный вес в общей семантической структуре предложения» [Иофик 1972: 65]. Эти особенности обособленного члена предложения, дающего углубленную характеристику предмету благодаря возникновению полупредикативной связи, позволяют ему стать одним из главных компонентов актуального членения, носителем ремы высказывания. 
Следует подчеркнуть, что все отмеченные характеристики обособленного определения предполагают наличие определенных условий для обособления, позволяющих только ограниченному кругу языковых элементов выступить в этой роли. Среди них обычно упоминаются такие структурные условия, как значительный объем обособляемой группы, особый порядок слов, дистантное расположение, однако, как показало наше исследование, имеются гораздо более существенные семантикосинтаксические условия, способные повлиять на перераспределение синтаксических связей. Ими являются элементы основной предикации, и, прежде всего, тип и семантика сказуемого в предложении, способ выражения и семантика самого определения, а также характеристика определяемого слова.

Анализ сказуемых в предложениях, включающих обособленные определения, выраженные причастиями и прилагательными с зависимыми словами, а также предложными оборотами, показал, что обособление становится более вероятным, если сказуемое является составным именным, причем обычно это семантически размытое и слишком обобщающее классифицирующее сказуемое. Например: "But under it all they were men, penetrating the land of desolation and mockery and silence..."[London 2007(2): 4]; "Lady Lucas was a very good kind of woman, not too clever to be a valuable neighbour to Mrs Bennet"[Austen 2006: 14]; "There were brighter pictures, of early Mexican-Californian life..."[London 2007(1): 83]. Во всех этих предложениях определения передают более яркие и существенные признаки определяемых слов, нежели признаки, обозначенные в сказуемых. Именно обособленные определения обладают наибольшей смысловой весомостью и коммуникативной важностью, они являются ремами этих высказываний, в то время как сказуемые преимущественно передают привычный или самый общий признак.

Соответственно, сами обособляемые элементы в подавляющем большинстве случаев являются носителями четкой и конкретной призначной семантики. В частности, среди причастий преобладают образованные от динамических глаголов, что повышает их предикативный потенциал, например: “A squirrel, running around the base of the trunk, came full upon him...”[London 2007(2): 69]; “...Mrs Bennet, accompanied by her two youngest girls, reached Netherfield” [Austen 2006: 31]. Качественные и относительные прилагательные обособляются, если обозначают временный, непостоянный признак, который является особенно существенным в данный момент и зачастую носит оттенок причины, например: “She opened the door, and met Maria... who, breathless with agitation, cried out..." [Austen 2006: 119]; "He backed away, stiff-legged with self-consciousness, and tried to go around her." [London 2007: 216]. Предложные обособленные определения обычно представляют отличительную характеристику, выделяющую предмет среди себе подобных, например, “А young girl, in rose-coloured kimono and boudoir 
cap, was at the instrument..."[London 2007 (1): 25]); "The sled itself was... a birch-bark toboggan, with upturned forward end to keep it from ploughing under the snow." [London 2007(2): 120].

Таким образом, собранный материал свидетельствует, что обособленные определения по своему содержанию представляют в большинстве случаев не добавочную информацию, как часто пишут лингвисты [см., например, Валгина 2003:229; Гак 2004:728], а как раз наиболее существенные сведения, что, несомненно, связано с ослабленной семантической нагрузкой сказуемого. Можно согласиться с мыслью А.Н.Гвоздева, что «..определяющим условием обособления является достаточный семантический вес второстепенного члена, необходимость и желательность его подчеркивания и выделения»[Гвоздев 1968:150]. Обособленное определение принимает на себя функцию выделения наиболее релевантного в описываемой ситуации признака, что значительно повышает его семантико-синтаксический статус в составе предложения по сравнению с обычным определением, приближая его к статусу главных членов.

Особенности определяемых обособленными определениями слов оказались глубоко взаимосвязанными с вышеописанными характеристиками самих определений. В частности, подавляющее большинство определяемых являются одушевленными конкретными существительными, что представляется вполне закономерным, учитывая динамический характер глаголов, от которых образованы большинство определений-причастий, временный характер признаков, выраженных прилагательными, а также яркий, часто обстоятельственный потенциал предложных определений. Представляется естественным, что именно конкретное лицо скорее будет охарактеризовано такими определениями, нежели неодушевленный предмет или абстрактное понятие. Приведем примеры: "Young Dick, kneeling and holding, watched.” London 2007(1): 52]; “... and his daughter, frightened almost out of her senses, sat on the edge of her chair..." [London 2007(2): 121]; "Kiche attacked him a third time, intent on driving him away altogether from the vicinity.”[London 2007(2): 134]; "Elizabeth, at work in the opposite corner, saw it all with great delight.”[Austen 2006: 41].

Подводя итоги, отметим, что выявленные нами тенденции в функционировании обособленных определений подтверждают полупредикативный характер синтаксических связей между такими определениями и определяемыми, возникающих во включающих предложениях, о чем может свидетельствовать и возможность трансформации любого обособляемого определения в предикативную единицу. Все выявленные факторы обособления: ослабленный семантический вес сказуемного признака; особая значительность, яркость и релевантность для ситуации признаков, выраженных самими определениями; преимущественная отнесенность этих признаков конкретным лицам глубоко взаимосвязаны между собой и способствуют повышению статуса 
обособленного определения в предложении по сравнению с необособленным определением. Соответственно, обособленное определение вряд ли можно причислить к второстепенным членам предложения, оно, скорее, сближается с главными членами, занимает промежуточную синтаксическую позицию, подтверждая идею всеохватывающей недискретности языковых явлений и отсутствия между ними жестких границ.

\section{ЛИТЕРАТУРА}

1. Валгина Н.С. Современный русский язык: Синтаксис. - М.: Высшая школа, 2003. $-416 \mathrm{c}$.

2. Гак В.Г. Теоретическая грамматика французского языка - М.: Добросвет, 2004. $862 \mathrm{c}$.

3. Гвоздев А.Н. Современный русский язык. Синтаксис. - М.:Просвещение, 1968.$343 \mathrm{c}$.

4. Грамматика современного русского литературного языка. - М.: Наука,1970.$688 \mathrm{c}$.

5. Иофик Л.Л. Структурный синтаксис английского языка. - Л. Издательство ЛГУ, 1972. $-176 \mathrm{c}$.

6. Смирницкий А.И.Синтаксис английского языка. - М.: Издательство ЛКИ, 2007. 296c.

7. Austen J. Pride and Prejudice. - М.: Юпитер-Интер, 2006. - 292c.

8. London J. The Little Lady of the Big House. - Новосибирск: Сиб. унив. изд-во, 2007. - 292c. (1)

9. London J. The White Fang. - Новосибирск: Сиб. унив. изд-во, 2007. - 166с. (2) 